\title{
Impact of climate change on the outbreak of infectious diseases among children in Bangladesh
}

\author{
A. K. M. Kamruzzaman', Md. Sarwar Jahan², Md. Redwanur Rahman², Most. Manzuara Khatun ${ }^{3}$ \\ ${ }^{1}$ Public Health and Child health specialist, Rajshahi, Bangladesh \\ ${ }^{2}$ Institute of Environmental Science, University of Rajshahi, Rajshahi-6205, Bangladesh \\ ${ }^{3}$ Assistant Professor, Department of Anatomy, Islami Bank Medical College, Rajshahi, Bangladesh
}

Email address:

zamankwho@yahoo.com (A. K. M. Kamruzzaman), insenv_ru@yahoo.com (M. S. Jahan), redwan_rahman@lycos.com (M. R. Rahman), monzuara16@yahoo.com (M. Khatun)

\section{To cite this article:}

A. K. M. Kamruzzaman, Md. Sarwar Jahan, Md. Redwanur Rahman, Most. Manzuara Khatun. Impact of Climate Change on the Outbreak of Infectious Diseases among Children in Bangladesh. American Journal of Health Research. Vol. 3, No. 1, 2015, pp. 1-7.

doi: 10.11648/j.ajhr.20150301.11

\begin{abstract}
The impact of climate change and global warming are worldwide and global concern. Bangladesh is unfortunately home to many infectious diseases. Climate change related events like temperature, rainfall, humidity etc. have direct and indirect adverse impacts on the outbreak of infectious disease among children. A number of water, air and vector borne infectious diseases including diarrhoea, measles, rubella, kala-azar, malaria and dengue etc. are common in Bangladesh. A cross sectional study was carried out to observe the impact of climate factors on the incidence of air borne infectious disease among children in Bangladesh. The methodology of the study includes analysis of both secondary and primary data. Results showed the long-term changes of annual mean, maximum and minimum temperature of study area over the study period (1964-2011) found to have in general increasing trends in annual mean and annual mean minimum temperature but the mean maximum temperature slightly rising in recent past decades. Seasonal mean temperatures are also found to have increased trend. The long-term changes in annual rainfall that showed declining trend. Seasonal rainfalls also showed markedly reduced in winter and post autumn season. The primary data reveals that temperature is the main and rainfalls comes next as influencing factor for air borne measles like disease and their outbreak among children. The incidence of measles like disease was found positive correlation with maximum temperature and negatively correlated with average minimum temperature and total annual rainfalls. However, the current understanding of the impact of climate change on the outbreak of air borne infectious disease is not sufficient. To address the existing and future impact of climate change on the outbreak of infectious diseases among children, climate sensitive infectious disease surveillance and continuous monitoring to be considered and further studies are needed.
\end{abstract}

Keywords: Climate Change, Air Borne Infectious Disease, Measles, Rubella

\section{Introduction}

Climate is a determinant of health. Climate and weather are important components of complex ecosystems. Climate constrains the range of infectious diseases, whereas weather affects the timing and intensity of outbreaks. All infections involve an agent (or pathogen), host(s), and the environment. Climate can influence pathogens, vectors, host defenses, and habitat. Infectious diseases continue to be the major cause of morbidity and mortality worldwide. Bangladesh is unfortunately home to many infectious diseases. Over the last several decades Bangladesh has made remarkable progress in reducing the human health burden of infectious disease, especially in children, largely due to reduction in mortality from infectious diseases. Despite substantial progress, vaccine preventable airborne infectious diseases like measles remain as important causes of ill health and premature death in Bangladesh. In the most recent national demographic and health survey (year 2011) $62 \%$ of deaths among children under the age of 5 years in Bangladesh were ascribed to infectious diseases. The use of vaccines results in a profound alteration of the environment in which parasites live. Indeed, the goal of vaccination is to protect individual hosts and consequently decrease parasite prevalence. Ultimately, this may even lead to the eradication of the disease [1]. These epidemiological consequences of vaccination have received a considerable amount of attention, both from an empirical and 
a theoretical standpoint [2], [3]. There were some researches and studies on climate change and its impacts in Bangladesh at different times by both government and non-government organization and institutions. There is very little information about climate change and airborne infectious disease burden in Bangladesh.

\subsection{Climate Change in Bangladesh}

The Bangladesh Country Study for the U.S. Country Studies Program used an older version of the Geophysical Fluid Dynamics Laboratory (GFDL) transient model and projected that temperature would rise $1.3^{\circ} \mathrm{C}$ by 2030 (over mid-20th century levels) and $2.6^{\circ} \mathrm{C}$ by 2070 . The report estimated that winter warming would be greater than summer warming. The study also estimated little change in winter precipitation and an increase in precipitation during the monsoon [4]. Second major work was also conducted by [5], where they attempted to characterize changes of Bangladesh climate. The research showed that the annual and seasonal mean temperatures are found to have in general increasing trends in Bangladesh. The overall trend in mean annual temperature was found to be +0.10 and $+0.210 \mathrm{C}$ per decade for years 1948 to 2007 and 1980 to 2007 respectively. It concludes that warming has been more rapid in recent decades.

\subsection{Climate and Human Health}

Knowledge of the interactions between climate and health date back to the time of Aristrotole, but our understanding of this subject has recently progressed rapidly as technology has become more advanced. Evidence is mounting that changes in the broad-scale climate system may already be affecting human health, including mortality and morbidity from extreme heat, cold, drought or storms; changes in air and water quality; and changes in the ecology of infectious diseases [6]. Climate change also brings new challenges to the control of infectious diseases. Many of the major killers are highly climate sensitive as regards to temperature, humidity and rainfall, including air born (measles) and the water born (diarrhoeal) diseases, as well as diseases including malaria, kala azar, dengue and other infections carried by vectors.

\subsection{Climate Change and Air Borne Infectious Diseases Outbreak}

Climate is one of several important factors influencing the incidence of infectious diseases. The combination of higher temperatures and potential increases in summer precipitation could create the conditions for greater intensity or spread of many air borne infectious diseases. The causes of outbreaks of infectious disease are quite complex and often do not have a simple relationship with increasing temperature or change in precipitation. Pathogens of air borne infectious diseases are normally transmitted directly between two human hosts through physical contact or droplet exposure. The transmission cycle of these diseases comprises two elements: pathogen and human host. Generally, these diseases are least likely to be influenced by climatic factors since the agent spends little to no time outside the human host. These diseases are susceptible to changes in human behavior, such as crowding, schooling, socio-cultural gathering and inadequate sanitation that may results from climatic changes. Directly transmitted airborne infectious diseases includes measles, rubella, mumps, and tuberculosis [7].

\subsubsection{Measles}

Measles is the most contagious disease known to man. It is a major childhood killer in developing countries - accounting for about 900000 deaths a year. The mean age of infection is about 9-12 months but varies among countries in large part due to differences in passive immunity provided from mother to child through trans placental antibody transfer, childhood nutrition and national vaccination schedules. The measles virus may ultimately be responsible for more child deaths than any other single microbe due to complications from pneumonia, diarrhoea and malnutrition. Measles is a human disease and is not known to occur in animals. Although vaccine initiatives have had considerable success in reducing its impact, measles continues to be a serious global health burden. In earlier studies, pre-vaccine measles incidence often exhibited a strong annual or biannual pattern. Epidemics begin as early as September and as late as December or January. The epidemics were peak in the spring, often in late March or early April [1].

Prior to the availability of measles vaccine, measles infected over $90 \%$ of children before they reached 15 years of age. Though childhood immunization program has markedly increases its coverage in Bangladesh but still now it is one of the major causes of mortality and morbidity in children.

\subsubsection{Transmission}

The highly contagious viruses spread by coughing and sneezing, close personal contact or direct contact with infected nasal or throat secretions. The virus remains active and contagious in the air or on infected surfaces for up to two hours. It can be transmitted by an infected person from four days prior to the onset of the rash to four days after the rash erupts. Transmission, which is primarily by large respiratory droplets, increases during the late winter and early spring in temperate climates and after the rainy season in tropical climates.

\subsubsection{Measles Outbreak}

Measles outbreaks can be particularly deadly in countries experiencing or recovering from a natural disaster or conflict. The major factors that determine the epidemic spread of measles are the accumulation of the susceptible and new migrant that have not suffered from disease in a community and the inevitable exposure to infection. Measles outbreaks can result in epidemics that cause many deaths, especially among young, malnourished children. Epidemics may still occur every 2 or 3 years in areas where there is low vaccine coverage. According to the current measles control strategy of Bangladesh measles outbreak is defined as an occurrence of 3 or more suspected measles cases in one month in a rural 
ward/urban mahalla.

\subsubsection{Rubella}

Rubella is an acute, usually mild viral disease traditionally affecting susceptible children and young adults worldwide. Rubella is an airborne infectious disease usually occurs in seasonal pattern, with epidemics every 5-9 years and humans are the only known host. However, the extent and periodicity of epidemics is highly variable in both industrialized and developing countries [8]. The public health importance of rubella is due mainly to the teratogenic potential of the viruses if infection occurring just before conception or in early pregnancy may result in miscarriage, fetal death, or congenital defects known as congenital rubella syndrome.

Clinically sign symptoms of rubella mimics' measles. In Bangladesh case definition of measles covered rubella disease.

\section{Materials and Methods}

The methodology of the study includes analysis of both secondary and primary data. This was a cross sectional comparative study. Infectious disease related data were collected from twenty Upazila Health Complex, one district hospital, two Civil Surgeon office and one City Corporation of the study area Rajshahi and Naogaon district and also from MIS of DGHS, Dhaka. Time series of climate factors data were collected from Bangladesh Meteorological Department Dhaka and from local weather station, Rajshahi for the period of years 1964 to 2011. Primary data were collected from the study area for the period of years 2009 to 2011. All collected data were analyzed by using computed based statistical software SPSS 19 . Pc program, and expressed as mean \pm SD or in frequency or in percentage. The level of significance was expressed in $p$ value and $\mathrm{p}$ value $<0.05$ was considered as a level of significance. Result used to find out the correlation association between climatic variables temperature, rainfalls and incidence of air borne infectious diseases. In addition, immunization status and incidence of vaccine preventable infectious disease also analyzed. Primary data collection tools include household survey, active case search at hospital facilities and in-depth interview with diseased individual or from attendant. The systemic random sampling technique was carried out in the household of the study areas. A total of 60 clusters including 420 samples were selected according to probability proportional to size (PPS) methods which is self-weighted. The main purpose of primary data collections were to collect the data on air borne infectious disease, vaccination status of the children, perception on climatic variables (temperature, rainfall), seasonal changes of climatic factors etc.

\section{Results and Discussion}

\subsection{Analysis of Secondary data}

The time series climatic data comprised monthly and annual mean, maximum and minimum temperature for the period of 1964-2011 and monthly and annual mean rainfall for the period of 1964-2011. The data were analyzed to find the seasonal, intra-seasonal and annual changes.

The long-term changes of annual maximum, mean and minimum temperature of study area over the study period (1964-2011) (Figure 1), found to have in general increasing trends in annual mean and annual mean minimum temperature but the mean maximum temperature slightly was decreasing in recent past decades. The study revealed that through the last 47 years (1964-2011) the annual mean temperature, annual mean minimum temperature has increased by $1.1^{0} \mathrm{C}$ and $3.5^{\circ}$ $\mathrm{C}$ respectively but the annual mean maximum temperature has decreased by $4.7^{0} \mathrm{C}$.

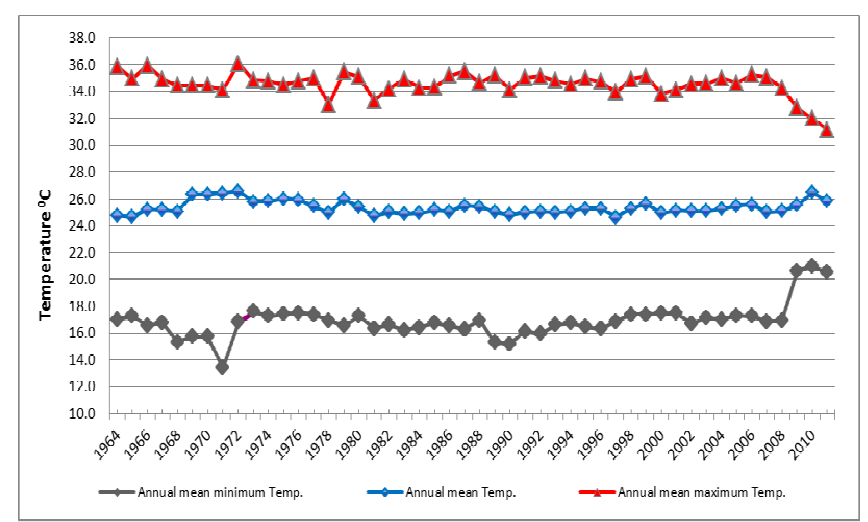

Figure 1. The annual mean minimum, mean and mean maximum temperatures in Rajshahi region during the period 1964-2011.

The long-term seasonal mean temperatures are also found to have increasing trend over the study period (1964-2011) (Figure 2). The highest average maximum temperature was $30.55^{\circ} \mathrm{C}$ observed in the month of April in pro monsoon season and the lowest average temperature was $15.45^{\circ} \mathrm{C}$ in the month of January in winter season.

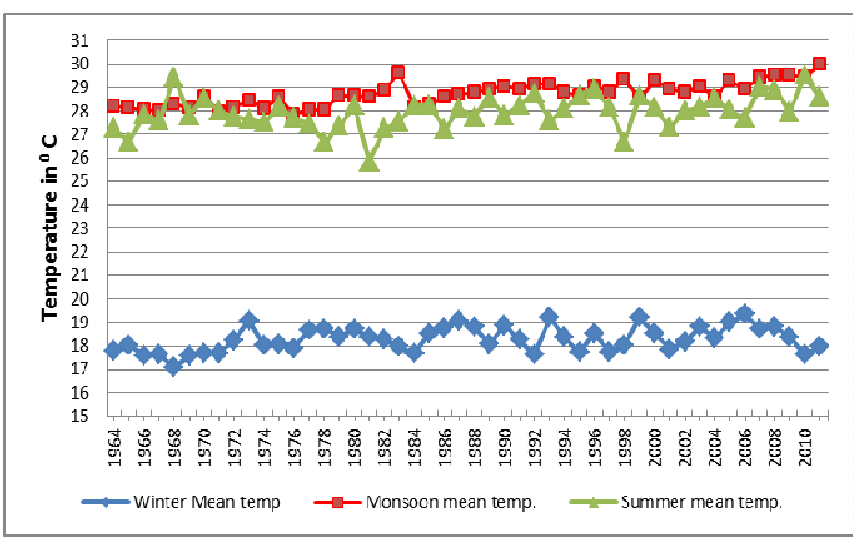

Figure 2. The annual winter mean, monsoon mean and summer mean temperatures in Rajshahi region during the period 1964-2011.

The figure 3 indicates that the long-term monthly minimum temperature in the study area over the study period (1964-2011) was lowest in the month of January and December which corresponds to the coldest months observed in winter season of Bangladesh. 


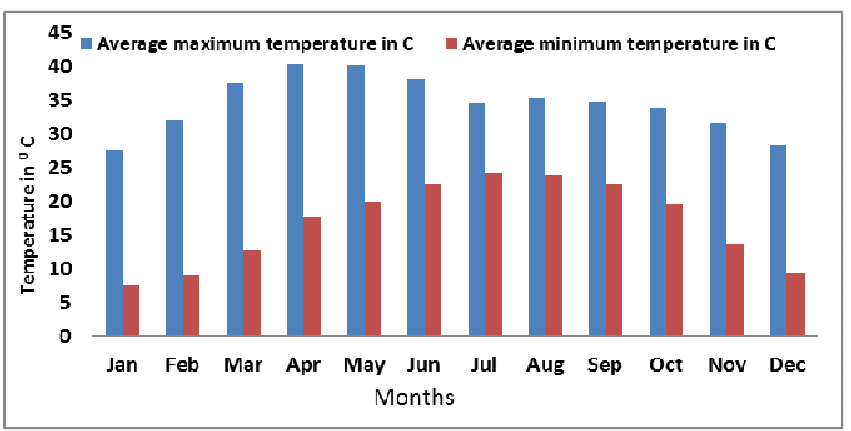

Figure 3. Monthly average maximum and minimum temperatures in Rajshahi region during the period 1964-2011.

The figure 3, also shows that the long-term monthly maximum temperature in the study area over the study period (1964-2011) was highest in the month of April and May which corresponds to hottest months observed in summer/pre monsoon season of Bangladesh.

\subsection{Trends in Rainfall in Study Area}

The long-term changes in annual rainfall in the study area over the period (1968-2011) showed (Figure 4), declining trends from last two decades. The average annual rainfall was $1489 \mathrm{~mm} /$ year.

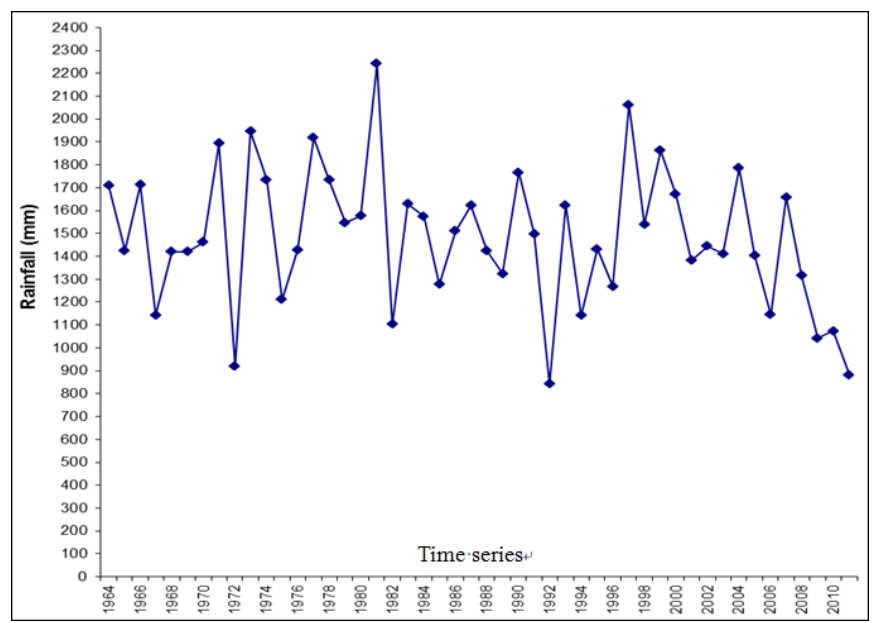

Figure 4. Annual average rainfall in Rajshahi during the year 1964-2011

The long-term seasonal rainfall in the study area (Figure 4), showing markedly reduced in winter and post autumn season. Most of the rainfall occurred in monsoon season that is also declined in the study area over the study period (1964-2011).

\subsection{Climate Sensitive Infectious Disease Profile}

In Bangladesh a good number of people suffer from air borne infectious disease like measles and other infectious disorders. The following figure show the annual incidence of air borne climate sensitive diseases like measles and their trend in Bangladesh.

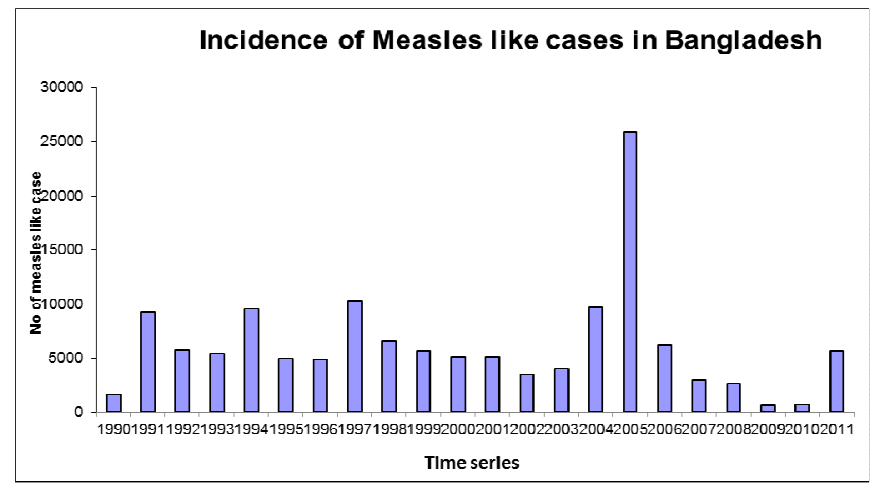

Figure 5. Incidence of Measles like cases in Bangladesh during the period of 1990-2011

Seasonal incidences of climate sensitive infectious diseases and their outbreak in each year over the study period were also observed. To explore the association between climate sensitive infectious diseases and climate factors correlation analysis was carried out using both secondary and primary data. Climate factors such as annual and seasonal rainfall, annual mean maximum and minimum temperature and climate sensitive diseases (e.g. Measles) were analyzed to find out the association between impacts of climate change on the outbreak of infectious diseases in the study area. Pearson's Coefficient method was applied to detect the extent of association between incidences of each disease and climatic factors. Data on climatic factors and incidences of climate sensitive infectious diseases from year 2000 to 2011 were used to find out the correlation.

A positive correlation implies that the greater the variation in the climatic factors the larger the number of incidences of diseases. The results of the correlation analysis between climatic factors and climate sensitive infectious diseases are shown below.

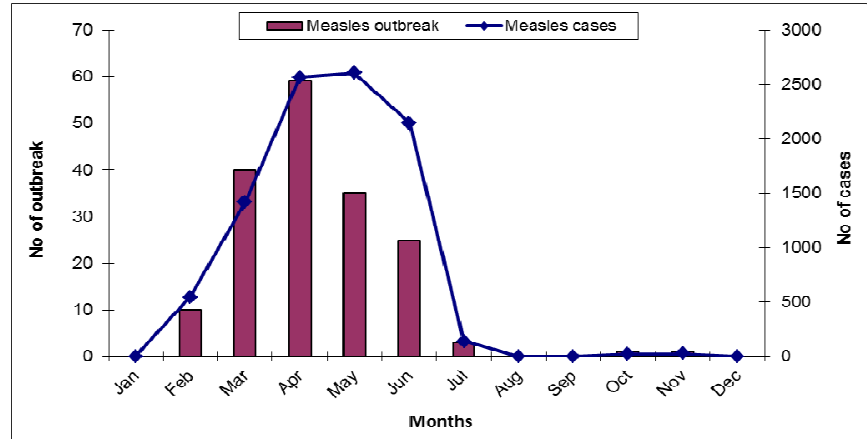

Figure 6. Incidence of Measles outbreak and cases in study area during the study period

Figure 6 shows most of the outbreak occurred in March, April and May, whereas number of cases highest in April, May and June. These 4 months corresponds to the summer season of Bangladesh. Measles were found (Table 1) to have positive correlation with both seasonal rainfall and annual average maximum temperature and negative correlation with annual rainfall. In winter there were significant positive impacts of rainfall with the increased number of patient. Negative 
correlation also found between measles like diseases and

annual average minimum temperature in the study period.

Table 1. Values of Correlation coefficient of climatic variables and Measles in study area during the study period (2000-2011)

\begin{tabular}{llll}
\hline \multicolumn{2}{l}{ Correlation on incidence of Measles and climate factors } & & \\
\hline Sl. No & Climate variables & Disease & Value of Correlation coefficient \\
\hline A & Total annual rainfall $(\mathrm{N}=12)$ & Measles & -0.475 \\
B & Total seasonal rainfall (N=12) & & \\
1 & Winter (Dec, Jan, Feb) & Measles & +0.899 \\
2 & Summer or Pre-monsoon (March, April, May) & Measles & +0.233 \\
3 & Monsoon (June, Jul, Aug, Sept) & Measles & -0.131 \\
4 & Autumn or Post monsoon (Oct, Nov) & Measles & +0.1000 \\
C & Annual average maximum temperature (N=12) & Measles & +0.967 \\
D & Annual average minimum temperature $(\mathrm{N}=12)$ & Measles & -0.003 \\
\hline
\end{tabular}

The incidences of measles like cases were found to have positive correlation with annual average maximum temperature $(+0.967)$ and seasonal winter $(+0.0899)$, summer and post monsoon $(+0.1000)$ rainfall. Negative correlation were found with total annual rainfall $(-0.0475)$, seasonal monsoon rainfall $(-0.131)$ and annual average minimum temperature (-0.003) (Table 1).

\subsection{Results from Primary Data}

This section deals with findings of 60 cluster sample using 30 cluster survey technique in two study districts and all reported infectious disease outbreak in the study period. In each cluster 7 household's respondent were included. The sample survey included a total of 420 households. Some demographic information and vaccination status of less than 5 years children were also recorded during house to house survey. The findings of the study have been assessed quantitatively and qualitatively to find correlation between impact of climate change and outbreak of infectious diseases among children.

\subsection{In-depth Investigation of Reported Outbreak in the Study Area}

During in-depth investigation of reported outbreak a prescribed line listing form was used and interviewed diseased person about the course of disease and their link with climatic variables. Regarding climatic variables, most of the respondent's mentioned that there is change in seasonal temperature, rainfall, humidity etc. Many of the respondents specially said that the lengths of summer and winter have been changed nowadays in comparison to the past. Average temperature is felt to be increasing in both summer and winter months in the study area. The length of winter shortened and came late in comparison to the past. Almost all the respondents gave opinion on temperature and rainfall variations.

A lot of information on course of disease were gathered from the measles like outbreak areas. In response to first reported cases (index case), a quick investigation performed to confirm the clinical diagnosis and blood sample collected for serological study. By tracking index cases (236 cases) in the community a total of 174 measles like outbreak was identified and clinically confirmed by case investigation and community searching with a prescribed outbreak investigation format during the study period (year 2009-2011) within the study area. From each outbreak site blood sample were collected from the clinically confirmed suspected measles like cases and serological study was conducted to identify the Immunoglobulin M (IgM) for measles and Immunoglobulin $\mathrm{M}$ (IgM) for rubella. On the basis of laboratory report measles like outbreak were classified as;

a) Confirmed measles outbreak- at least 2 sample measles IgM positive;

b) Confirmed rubella outbreak- at least 2 sample rubella IgM positive;

c) Mixed measles rubella outbreak- at least one measles and one rubella IgM positive; and

Discard outbreak- all sample negative for both measles and rubella. Laboratory report of Measles like outbreak investigation data revealed (Table-2) that out of 174 outbreaks, 11 were laboratory confirmed measles outbreak consisting of 491 cases, 126 laboratory confirmed rubella outbreak consisting of 8042 cases, 25 mixed measles and rubella outbreak consisting of 191 cases and 12 discarded as non-measles non rubella outbreak consisting of 456 case.

Table 2. Measles like Outbreak and Cases in the Study Area

\begin{tabular}{|c|c|c|c|c|c|c|c|c|}
\hline \multirow{2}{*}{ Year } & \multicolumn{2}{|c|}{ Lab confirmed Measles } & \multicolumn{2}{|c|}{ Lab confirmed Rubella } & \multicolumn{2}{|c|}{ Mixed measles \& rubella } & \multicolumn{2}{|c|}{ Discarded outbreak } \\
\hline & No of $\mathrm{OB}$ & No of case & No of OB & No of case & No of $\mathrm{OB}$ & No of case & No of $\mathbf{O B}$ & No of case \\
\hline 2009 & 0 & 0 & 55 & 5338 & 0 & 0 & 4 & 140 \\
\hline 2010 & 0 & 0 & 55 & 2218 & 10 & 97 & 4 & 181 \\
\hline 2011 & 11 & 491 & 16 & 586 & 15 & 94 & 4 & 135 \\
\hline Total & 11 & 491 & 126 & 8042 & 25 & 191 & 12 & 456 \\
\hline
\end{tabular}

$\mathrm{NB}: \mathrm{OB}=$ Outbreak

A total of 491 laboratory positive measles case were identified during outbreak searching. The beginning spurt of the outbreak was in the month of January, gradually increased and peaked at April-May and declined thereafter. Second 
episode also found in October and November. There was no single incidence of measles case in the month of September and December during the study period (Figure 7).

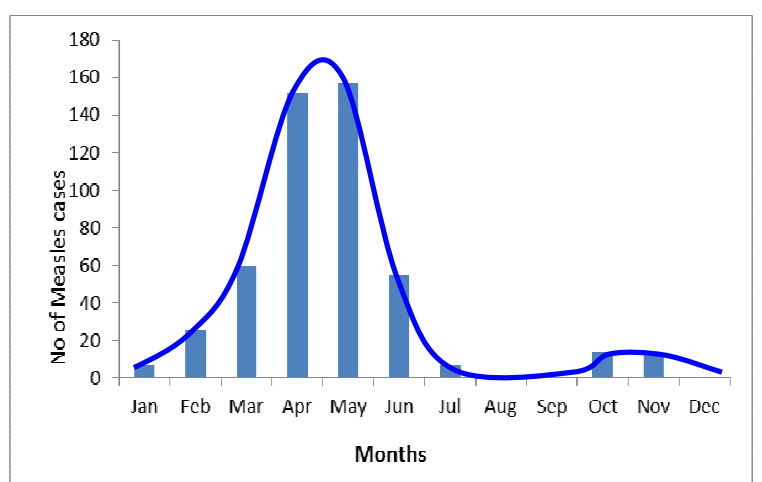

Figure 7. Epidemic Curve of Measles Outbreak in the Study Area during the study period (2009-2011)

Age distribution (Figure 8), and sex distribution (Figure 1.9), revealed that measles disease affected irrespective of sex and ages. The graph showed that $75.9 \%$ of the measles cases under 15 years age group. $3.6 \%, 2.3 \%, 20.4 \%, 29.5 \%, 20.1 \%$ of the measles cases were <9 months, 9-11 months, 1-4 years, 5-9 years, 10-14 years age group respectively. Besides this there was $23 \%$ patient more than 20 years age.

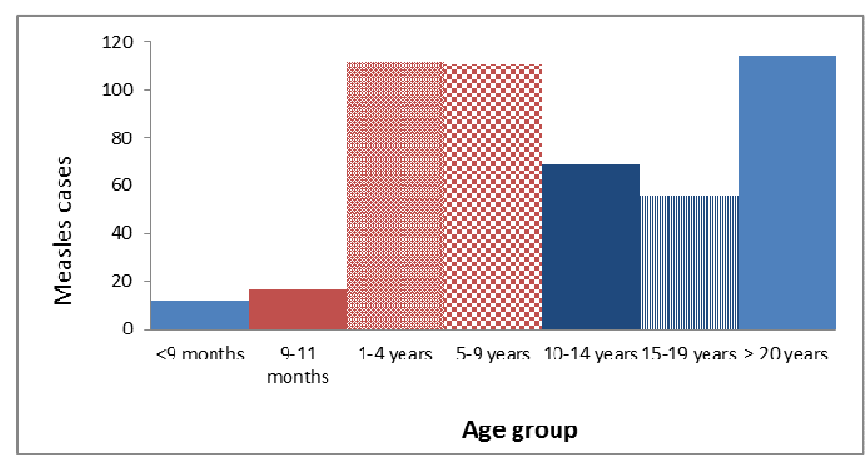

Figure 8. Age distribution of Measles cases in study area

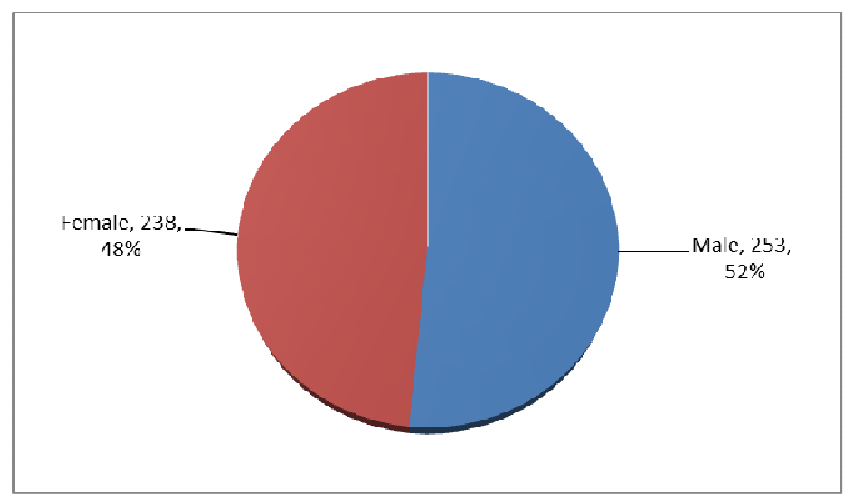

Figure 9. Sex Distribution of Measles Cases in the Study Area

Post measles complication: A period of one month after the attack of measles was taken into account for recording post measles complications. Parents reported one or more post measles complications in 54 cases out of 491 cases. Diarrhoea was the commonest $(74 \%)$ of all, followed by pneumonia
(25\%). There was no death due to measles like outbreak in the study area during the study period (2009-2011).

Figure 10 showed that there was an enormous lab confirmed rubella outbreak and rubella case in the year 2009 consisting 5238 cases, in the year 2010 consisting 2218 cases and in the year 2011 consisting 586 cases. On the contrary there was no lab confirm outbreak of measles during 2009-2010 but 491 cases lab confirmed measles cases were diagnosed in 2011.

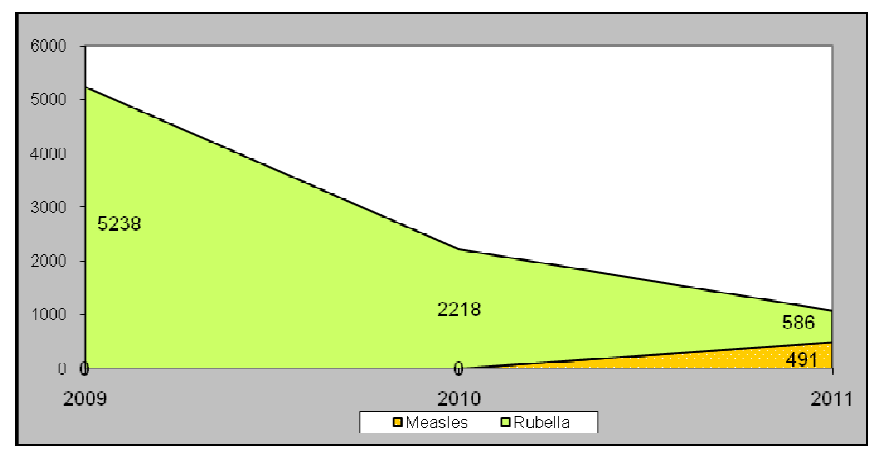

Figure 10. Comparison of Measles like Outbreak Cases by Lab result in the study area

Incidences of infectious diseases in human not only influenced by climatic factors but also depend on nutritional status, immunization status, socio-economic and educational status of the individuals, family and community. The greatest effects of climate change on transmission of infectious diseases are likely to be observed at the extreme ranges of temperatures at which transmission occur (Ranges between $14-18^{\circ} \mathrm{C}$ and $35-40^{\circ} \mathrm{C}$ ) [9]. The present study has revealed changes in the trend of climate factors particularly yearly and seasonal mean, maximum and minimum temperature and rainfall over the last three decades in the study area. The long-term changes of temperature of study area over the period (1964-2011) found to have in general increasing trends in annual mean and annual mean minimum temperature but the annual mean maximum temperature slightly declining in recent past decade. Similar results were also observed by [10] [11]. The long-term changes in annual and seasonal rainfall in study area showed slightly decreasing trend with markedly reduced winter and post monsoon season rainfall in recent past decade supported by CCC, Bangladesh 2009 report and [11]. The results of the study indicate that the climatic factors including temperature and rainfall (seasonal and annual) might have relation with air borne infectious disease outbreak like measles among children in the study area. The study disclosed that though measles vaccination coverage in the study area was $94.17 \%$ in 9 months to under 15 years age group nevertheless a good number of measles cases were confirmed in the laboratory test. It might be either the vaccination failure or factors of the individuals were not synergistic to the vaccine. Besides this there was $23 \%$ patients of more than 20 years age. which was uncommon in measles epidemiology. It showed that there was a shift in age group affected towards higher side. Similar observations were also reported by [12], [13] and [14]. In addition to laboratory 
confirmed measles outbreak a large number of measles like outbreak identified as laboratory confirm rubella outbreak which is newer in the study area that needs attention for assessing rubella and congenital rubella syndrome burden in the study area as well as in the country. The incidence of measles like disease was found to reflect positive correlation with maximum temperature $(+0.967)$ and negatively correlated with average minimum temperature $(-0.003)$ and total annual rainfalls $(-0.475)$. That is outbreak of measles like cases was found during the prevailing highest temperature in the month of March-May and declined after heavy rainfall and during winter months. Whereas the measles epidemics exhibit annual seasonality in which epidemics start in the autumn and peak in the spring (Fine \& Clarkson, 1982, London and Yoke, 1973) in western country. This variation of seasons for measles outbreak might be due to the locale climatic variation which confirms the positive influence of climatic changes on infectious diseases. It has been found that drought and high temperature favors the transmission of the virus. The changing trends of rainfall and temperature in the study area may favor the measles outbreak in coming days if appropriate measures could not be taken.

\section{Recommendation}

Data related to climatic variables and infectious disease report in the context of specific location of Bangladesh makes the interpretation of the results of the study quite difficult. So an extensive and in-depth study should be undertaken for better understanding of the impacts of climate change on the outbreak of infectious diseases especially among children.

\section{Acknowledgements}

Authors are thankful to Bangladesh Meteorological Department Dhaka and local weather station, staff members of Civil surgeon office, Upazila Health Complexes, City Corporation, Department of the Community Medicine, Govt. Medical College Rajshahi for their cooperation and help.

\section{References}

[1] P.E. Fine, and J.A. Clarkson, Measles in England and WalesAn analysis of factors underlying seasonal patterns, International Journal of Epidemiology, 1982, vol. 11, pp 5-14.
[2] R.M. Anderson, B.T. Grenfell and R.M. May, Oscillator fluctuations in the incidence of infectious disease and the impact of vaccination: time series analysis. J. Hyg. 1991. Vol. 93, 587-608.

[3] A.J. McMichael, Population, environment, disease, and survival: past patterns, uncertain futures. Lancet, 2002, vol. 359, pp1145-1148.

[4] A.U. Ahmed, and M. Alam, Development of Climate Change Scenarios With General Circulation Models, in S. Huq, Z. Karim, M. Asaduzzaman, and F. Mahtab (Eds.), Vulnerability and Adaptation to Climate Change for Bangladesh, Kluwer Academic Publishers, Dordrecht, 1998, pp13-20.

[5] CCC, Climate Change and Health Impacts in Bangladesh. Climate Change Cell, DoE, MoEF; component 4b, CDMP, MoFDM. June, 2009, Dhaka.

[6] J.A. Patz, P.R. Epsten, T.A. Burke and J.M. Balbus, Global Climate Change and Emerging Infectious diseases, J. Am. Med Assoc. 1996, vol. 275, pp217-223.

[7] M.L. Wilson, J.L. Aron, J.A. Patz, and Baltimore, Ecology and infectious disease. In: Ecosystem change and public health: a global perspective' USA, John Hopkins University Press, 2001, pp.283-324.

[8] WHO position paper "Weekly epidemiological record" Rubella vaccine. 2011, vol. 29, issue 86, pp301-316

[9] D.J. Bradley, Human tropical diseases in a changing environment' Ciba Foundation Symposium, 1993, vol. 175, pp146-62.

[10] M. Ara, M. A. Hossain and M.M. Alam, Surface dry bulb temperature and its trend over Bangladesh, J. Bangladesh Aca. Sci., 2005, vol. 29, issue 1, pp29-40.

[11] M.G. Ferdous, and M. A. Baten, Climatic Variables of 50 Years and Their Trends over Rajshahi and Rangpur Division. J. Environ. Sci. \& Natural Resources, 2001, vol. 4, issue 2, pp147-150.

[12] J.S. Thakur, Measles outbreak in a peri urban area of Chandighar: Need for improving vaccine coverage and strengthing surveillance' Indian Journal of pediatrics, 2002, vol. 69 .

[13] T. Sydenham, History and Cure of Acute Diseases. 'The Relationship Between Local Temperature Range and Annual Seasonality of Measles in The United States: $1924-1948$ '. (The Classics of Medicine Library, 1979), 1979, pp46-50.

[14] W.P. London, and J.A. Yorke, Recurrent outbreaks of measles, chickenpox and mumps: Seasonal variation in contact rates'. American Journal of Epidemiology, 1973, vol. 98, pp453-468. 